\section{U.S. DEPARTMENT OF ENERCY}

\section{Office of}

ENERGY EFFICIENCY \& RENEWABLE ENERGY

\section{Thermal Energy Storage Systems for Buildings Workshop:}

Priorities and Pathways to Widespread Deployment of Thermal Energy Storage in Buildings

September 2021 


\section{Disclaimer}

This work was prepared as an account of work sponsored by an agency of the United States Government. Neither the United States Government nor any agency thereof, nor any of their employees, nor any of their contractors, subcontractors, or their employees, makes any warranty, express or implied, or assumes any legal liability or responsibility for the accuracy, completeness, or any third party's use or the results of such use of any information, apparatus, product, or process disclosed, or represents that its use would not infringe privately owned rights. Reference herein to any specific commercial product, process, or service by trade name, trademark, manufacturer, or otherwise, does not necessarily constitute or imply its endorsement, recommendation, or favoring by the United States Government or any agency thereof or its contractors or subcontractors. The views and opinions of authors expressed herein do not necessarily state or reflect those of the United States Government or any agency thereof, its contractors or subcontractors. 


\section{Authors}

The authors of this report are:

Nelson James, National Renewable Energy Laboratory (NREL)

Sumanjeet Kaur, Lawrence Berkeley National Laboratory (LBNL)

Fredericka Brown, American Association for the Advancement of Science Fellow

Marcus Bianchi, NREL

Judith Vidal, NREL

Diana Hun, Oak Ridge National Laboratory (ORNL)

The technical manager of this report is:

Sven Mumme, U.S. Department of Energy (DOE)

\section{Acknowledgments}

The execution of the Thermal Energy Storage Systems for Buildings Workshop was made possible thanks to tireless efforts of the organizing committee, consisting of personnel from DOE's Building Technologies Office, NREL, LBNL, and ORNL.

The outcomes presented in this workshop report would not be possible without the contributions of all the workshop attendees and their willingness to share insights and experiences. We would like to thank speakers and presenters who helped set the tone for the workshop and engage the audience.

The report authors extend thanks to the breakout session facilitators and notetakers who assisted in guiding discussion and documenting feedback. These include Chuck Booten, Michael Deru, Brian Fricke, Kyle Gluesenkamp, Anurag Goyal, Joe Hagerman, Chioke Harris, Ransisi Huang, Ravi Kishore, Eric Kozubal, Emily Laidlaw, Allison Mahvi, Jeff Munk, Kashif Nawaz, Wale Odukomaiya, Anna Pohlad, Kerry Rippy, Kedar Shete, Som Shrestha, Kim Trenbath, Jason Woods, and Helia Zandi.

We also give special thanks to Linh Truong, Lindsey McGuirk, and the rest of the NREL communications team for managing correspondence with participants and providing technical support for the workshop.

Finally, we acknowledge the financial support from the Building Technologies Office, which enabled us to organize and conduct this workshop. 


\section{List of Acronyms}

BTO Building Technologies Office

DOE U.S. Department of Energy

DR demand response

GEB grid-interactive efficient buildings

HVAC heating, ventilating, and air conditioning

LBNL Lawrence Berkeley National Laboratory

NREL National Renewable Energy Laboratory

OEM original equipment manufacturer

O\&M operation and maintenance

ORNL Oak Ridge National Laboratory

PCM phase change material

TES thermal energy storage

TOU time of use 


\section{Executive Summary}

The 2021 U.S. Department of Energy's (DOE) “Thermal Energy Storage Systems for Buildings Workshop: Priorities and Pathways to Widespread Deployment of Thermal Energy Storage in Buildings" was hosted virtually on May 11 and 12, 2021. This report provides an overview of the workshop proceedings. Organized by DOE's Building Technologies Office (BTO), the National Renewable Energy Laboratory, Lawrence Berkeley National Laboratory, and Oak Ridge National Laboratory, the workshop convened more than 600 stakeholders from around the world to discuss the need for advancing the deployment of thermal energy storage (TES) in buildings. This workshop was designed to build on BTO's webinar series ${ }^{1}$ and 2019 workshop. ${ }^{2}$ The goals of this workshop were to promote discussion on TES related to:

1. Market adoption and deployment barriers

2. Key applications and value drivers

3. System cost, performance, and market requirements

4. End-use specific needs.

The workshop took place over two days and consisted of keynote presentations, moderated panels, breakout sessions, and open discussion forums. The keynote presentations introduced opportunities for building TES, barriers to widespread deployment, and future visions. Moderated panel discussions presented diverse perspectives, breakout sessions provided opportunities for more intimate conversations, and open discussions captured feedback from the entire workshop group. Over the course of the two days, attendees exchanged experiences and ideas surrounding multiple aspects of TES in buildings.

The first section of this report provides background on the motivations behind advancing TES for residential and commercial buildings and elaborates on the workshop objectives. The second section details the workshop structure and participant demographics. The third section provides key findings of the discussions that took place during the breakout sessions. Finally, this report details recommendations and actions to increase the TES deployment. Several recommendations from workshop attendees are presented in Table ES-1.

TES holds significant potential to help increase building efficiency, grid-interactivity, and energy resilience, as well as reduce associated carbon emissions. The outputs generated from this workshop will aid stakeholders in advancing TES in buildings through a deeper understanding of the opportunities and barriers surrounding widespread deployment.

\footnotetext{
${ }^{1}$ DOE. “Thermal Energy Storage.” https://www.energy.gov/eere/buildings/thermal-energy-storage.

${ }^{2}$ Kaur, Sumanjeet, Marcus Bianchi, and Nelson James. 2020. 2019 Workshop on Fundamental Needs for Dynamic and Interactive Thermal Storage Solutions for Buildings. https://www.nrel.gov/docs/fy20osti/76701.pdf.
} 
Table ES-1. Workshop Attendee Recommended Initiatives

\begin{tabular}{|c|c|}
\hline Workshop Objectives & Recommended Initiatives \\
\hline \multirow{4}{*}{$\begin{array}{l}\text { Propose solutions to } \\
\text { overcome TES market } \\
\text { adoption and deployment } \\
\text { barriers }\end{array}$} & $\begin{array}{l}\text { Convene a TES consortium to better organize, focus, and } \\
\text { accelerate research and development efforts }\end{array}$ \\
\hline & Advance codes and standards for TES in building applications \\
\hline & Explore alternative market delivery mechanisms \\
\hline & Support training for installation and maintenance \\
\hline \multirow{3}{*}{$\begin{array}{l}\text { Identify key applications for } \\
\text { TES deployments }\end{array}$} & Develop prioritization guidelines for TES deployment \\
\hline & Identify locations with ideal rate structures for TES \\
\hline & Improve modeling capabilities to assess TES potential \\
\hline \multirow{3}{*}{$\begin{array}{l}\text { Identify performance and } \\
\text { market requirements for TES }\end{array}$} & Develop tunable and smart materials for high utilization \\
\hline & Prioritize lowering upfront capital cost \\
\hline & $\begin{array}{l}\text { Advance sensor and control capabilities for building and } \\
\text { community optimized solutions }\end{array}$ \\
\hline \multirow{4}{*}{$\begin{array}{l}\text { Explore technology-specific } \\
\text { solutions }\end{array}$} & Package TES solutions designed for easy installation \\
\hline & Develop diagnostic features to ensure proper TES installation \\
\hline & $\begin{array}{l}\text { Standardize certifying the performance and reliability of storage } \\
\text { components and systems }\end{array}$ \\
\hline & $\begin{array}{l}\text { Accelerate the rate at which novel research is transitioned to } \\
\text { market }\end{array}$ \\
\hline
\end{tabular}




\section{Table of Contents}

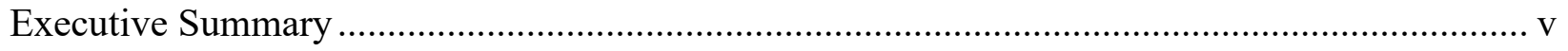

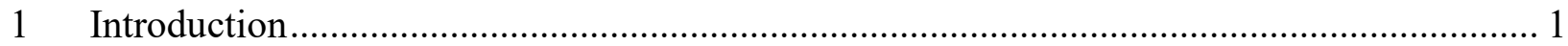

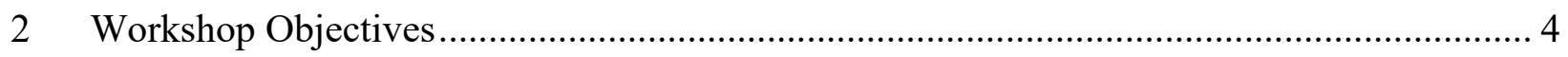

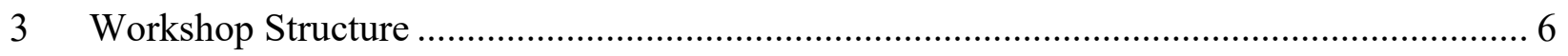

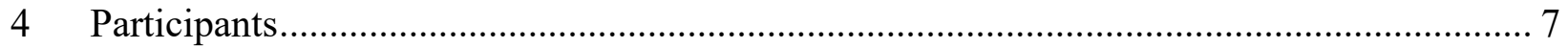

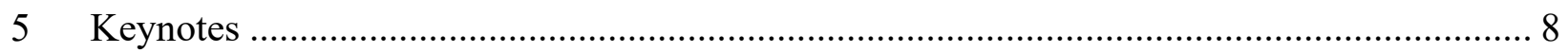

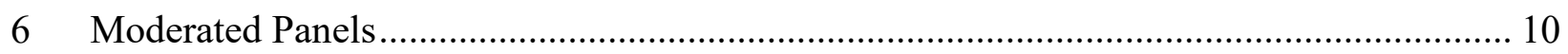

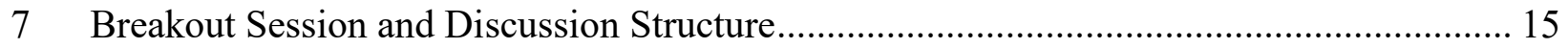

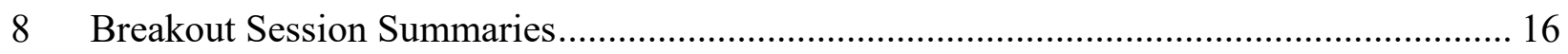

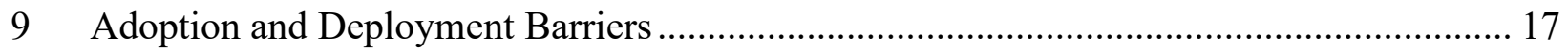

10 System Cost, Performance, and Market Requirements ........................................................ 20

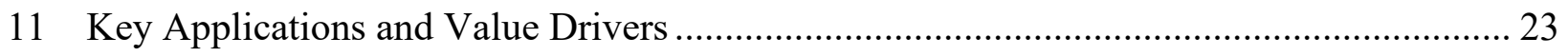

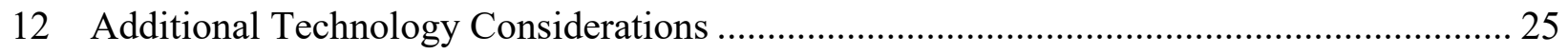

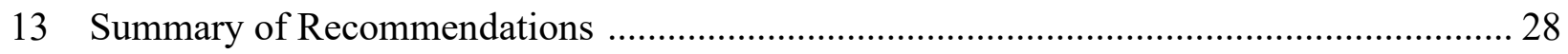

Appendix A. Workshop Agenda ................................................................................... 30

Appendix B. Presenter Biographies............................................................................... 32

Appendix C. Post-Workshop Survey .................................................................................. 39 


\section{List of Figures}

Figure 1. Annual electrical energy consumption in residential and commercial buildings for

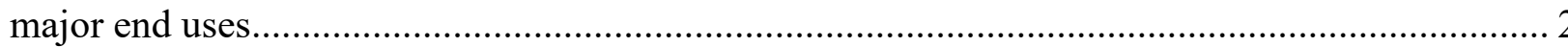

Figure 2. Peak period electrical energy consumption in residential and commercial buildings for

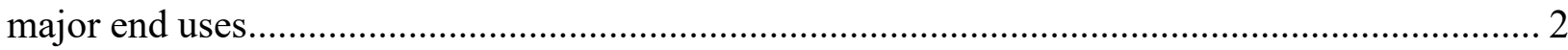

Figure 3. Projected market deployment of stationary Li-ion batteries and TES for buildings....... 3

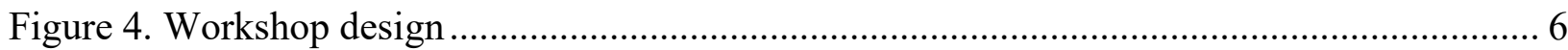

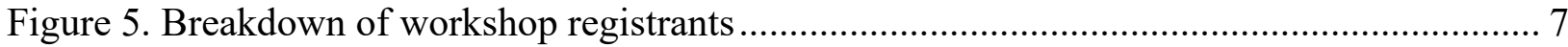

Figure 6. Depiction of a grid-interactive integrated energy ecosystem harnessing energy storage, renewable generation, and electric vehicle charging ........................................................ 8

\section{List of Tables}

Table ES-1. Workshop Attendee Recommended Initiatives ................................................. vi

Table 1. What are the biggest barriers to thermal energy storage (TES) adoption and deployment?

Table 2. What are some of the performance characteristics that are important when considering a TES system?.

Table 3. What advancements or partnerships would best encourage increased market demand for TES? 39

Table 4. What is the MOST important R\&D direction that needs to be pursued to enable increased commercialization of TES? 40

Table 5. How did you hear about the workshop? 


\section{Introduction}

This report presents the findings of the 2021 "Thermal Energy Storage Systems for Buildings Workshop: Priorities and Pathways to Widespread Deployment of Thermal Energy Storage in Buildings." Organized by the U.S. Department of Energy's (DOE) Building Technologies Office (BTO), the National Renewable Energy Laboratory (NREL), Lawrence Berkeley National Laboratory (LBNL), and Oak Ridge National Laboratory (ORNL), this virtual event was held on May 11 and 12, 2021. More than 600 stakeholders from around the world joined the workshop to discuss market deployment challenges for thermal energy storage (TES) technologies in buildings. The following sections detail the rationale, structure, and findings of the workshop.

\section{The Challenge}

The U.S. government has undertaken the ambitious goal of creating a carbon-pollution-free power sector by 2035 and a net-zero-emissions economy by 2050. Energy storage will undoubtedly play a key role in helping to achieve these objectives and will take on an increasingly important role in the U.S. energy ecosystem. In addition to the U.S. government's climate goals, the growth of electric vehicle usage, increased deployment of variable renewable generation, and declining costs of storage technologies are among other drivers of expected future growth of the energy storage market. By 2030 global energy storage markets are estimated to grow by $2.5-4$ terawatt-hours annually. ${ }^{3}$

Today, buildings consume $75 \%$ of all the electricity generated in the United States and are responsible for a comparably significant portion of peak power demands. ${ }^{4}$ The decarbonization of the building sector will be unavoidable in the pursuit of a clean energy economy. Storage sited at buildings can serve as important resources to promote grid reliability and flexibility, increase renewable penetration, and increase energy resilience. Current thermally driven loads make up more than $45 \%$ of the annual electrical energy consumed on-site in residential and commercial buildings (Figure 1). During peak load periods, the contribution of thermal loads can increase significantly (Figure 2). With expectations of future electrified heating loads in buildings, the annual electrical contribution of thermal loads in U.S. buildings may grow to more than $50 \%$, while peak period thermal loads may exceed $75 \%$ of building energy consumption.

\footnotetext{
${ }^{3}$ DOE. 2020. Energy Storage Market Report. https://www.energy.gov/energy-storage-grandchallenge/downloads/energy-storage-market-report-2020.

${ }^{4}$ U.S. Energy Information Administration. 2021. Annual Energy Outlook 2021. https://www.eia.gov/outlooks/aeo/.
} 
Business-as-usual
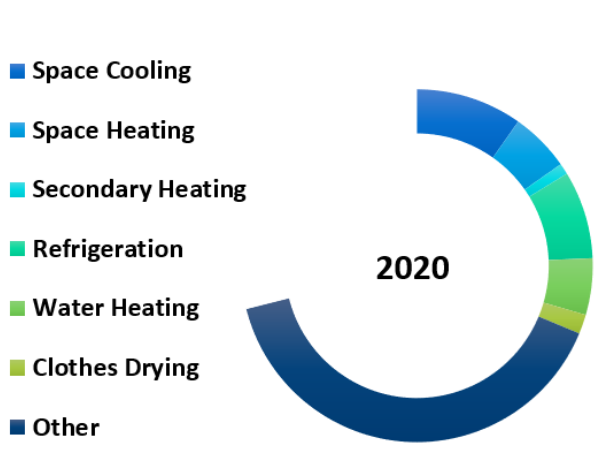

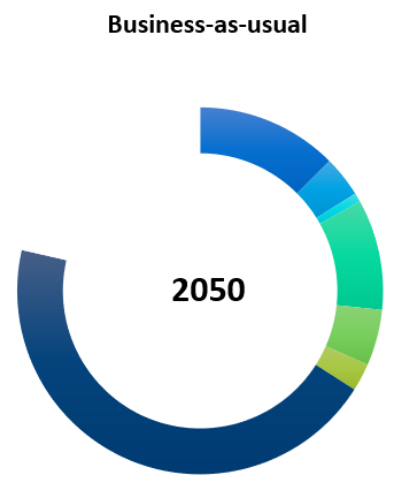

Fully Electrified Space and Water Heating Heat Pump COP 3

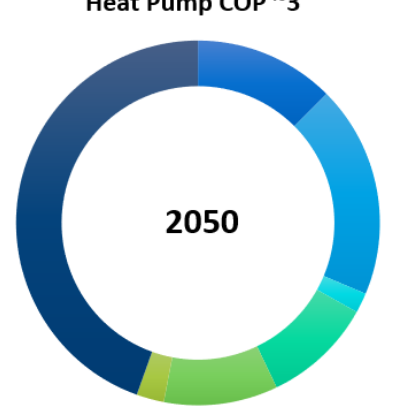

Figure 1. Annual electrical energy consumption in residential and commercial buildings for major end uses Data from: EIA (2021) and Scout (2021) ${ }^{4,5}$

Summer Peak Period

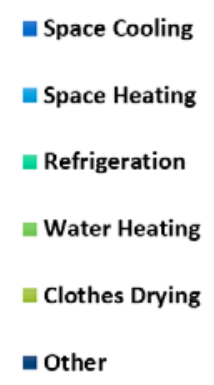

Business-as-usual

Summer Peak Period

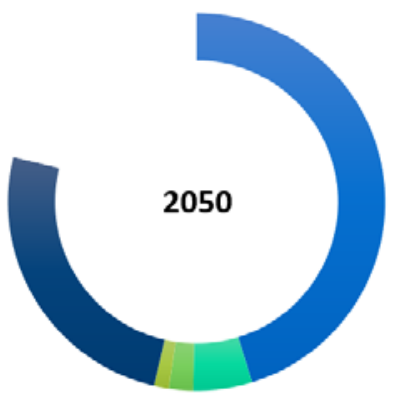

Fully Electrified Space Heating

Winter Peak Period

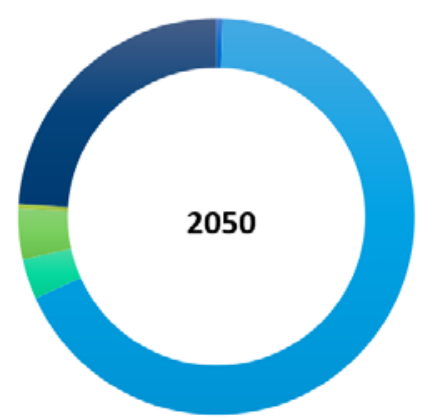

Figure 2. Peak period electrical energy consumption in residential and commercial buildings for major end uses

Data From: Scout $(2020)^{6}$

Given the significance of thermal loads to building electricity consumption, thermally based storage technologies can play an important role in managing energy for the built environment. Even though TES systems have the potential to be deployed at lower costs than electrochemical battery technologies, the market adoption of TES has lagged that of batteries. Current projections show the global TES capacity for buildings growing from around 600 megawatt-hours (MWh) to approximately 3,300 MWh over the next six years. Global deployments of lithium-ion (Li-ion) batteries for stationary applications are expected to grow from around 30 gigawatt-hours $(\mathrm{GWh})$ to around $85 \mathrm{GWh}$. Although the projected growth rate of TES deployments for buildings may

\footnotetext{
${ }^{5}$ DOE Building Technologies Office. Accessed: May 2021. "Scout Baseline Energy Calculator." https://scout.energy.gov/baseline-energy-calculator.html.

${ }^{6}$ DOE Building Technologies Office. 2020. "Scout v0.6." https://scout.energy.gov/.
} 
be greater than those of stationary Li-ion batteries, at current rates it may take decades for TES deployments in buildings to approach present day stationary Li-ion deployments. To reduce this disparity in adoption, DOE can support research initiatives to improve TES technologies for the built environment where it is applicable.

\section{Energy Storage Deployments}

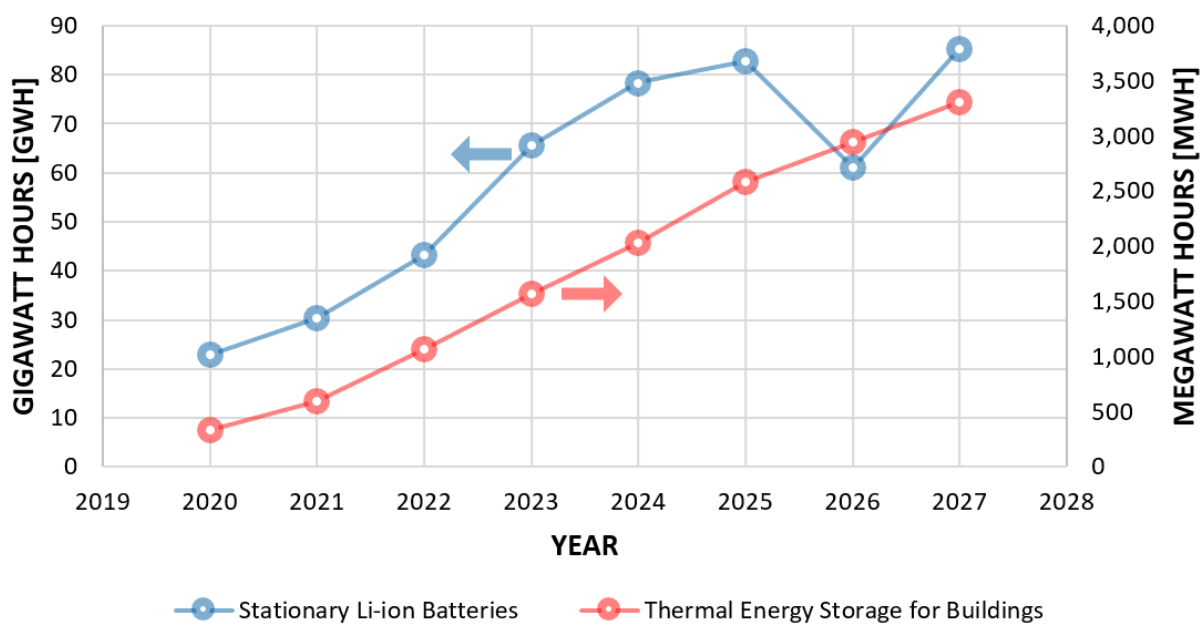

Figure 3. Projected market deployment of stationary Li-ion batteries and TES for buildings

Data From: DOE (2020)

TES materials are continually evolving, and many challenges remain for materials-level research for the next generation of storage media. In 2019, a workshop co-hosted by LBNL and NREL identified research opportunities to improve the capital cost, efficiency, utilization, and lifetime of TES materials. ${ }^{8}$ Materials-level research remains important, but investigations beyond material properties - such as system and integration challenges - may be required to accelerate the deployment of building-sited TES technologies.

\footnotetext{
${ }^{7}$ DOE. 2020. Energy Storage Market Report. https://www.energy.gov/energy-storage-grandchallenge/downloads/energy-storage-market-report-2020.

${ }^{8}$ Kaur, Sumanjeet, Marcus Bianchi, and Nelson James. 2020. 2019 Workshop on Fundamental Needs for Dynamic and Interactive Thermal Storage Solutions for Buildings. https://www.nrel.gov/docs/fy20osti/76701.pdf.
} 


\section{Workshop Objectives}

This workshop was designed to build on BTO's webinar series 9 and the 2019 "Workshop on Fundamental Needs for Dynamic and Interactive Thermal Storage Solutions for Buildings." The objective of this workshop was to focus on the latest system developments in TES and associated integration and market adoption challenges preventing the widespread deployment in buildings. Stakeholders were brought together to discuss state-of-the art TES technologies, identify technology gaps and research needs to overcome market adoption barriers, and develop input for a planned roadmap to coordinate and direct future pre-competitive R\&D and technology and market-scaling activities related to latent, sensible, and thermochemical TES for buildings.

Four primary areas of investigation were highlighted during the workshop: (1) TES market adoption and deployment barriers, (2) key applications and value drivers, (3) system cost, performance, and market requirements, and (4) end-use specific challenges.

\section{Market Adoption and Deployment Barriers}

Advanced TES technologies for buildings have not experienced the same meteoric rise in adoption rates as electrochemical batteries. This could be the result of a wide variety of factors, ranging from stakeholder education and awareness to lingering technical challenges. A thorough understanding of the obstacles faced by stakeholders such as building owners and utilities will be crucial to promoting rapid deployment of TES technologies. This workshop sought to identify technical and non-technical barriers limiting the adoption and deployment of TES technologies in buildings.

\section{Key Application and Value Drivers}

In addition to discussing obstacles to adoption, workshop attendees worked to define value streams that motivate the selection of TES technologies. Demographic differences such as building type, ownership, climate conditions, and utility structures influence the value that can be extracted from TES. As DOE strives to increase TES deployment, key applications must be identified where the adoption of this type of storage would be most advantageous. This workshop brought together stakeholders to discuss market pulls that encourage the increased deployment of TES technologies and applications as well as scenarios particularly promising for implementation.

\section{System Cost, Performance, and Market Requirements}

As energy storage technologies become more mainstream, stakeholders will come to expect certain levels of performance from their investments. As TES technologies compete with alternative storage methods, an understanding of the cost and performance expectations of end users for TES devices (i.e., a value proposition) will be critical for promoting increased market deployment. Workshop participants discussed system characteristics that will be required for increased adoption of TES technologies in buildings.

${ }^{9}$ DOE. “Thermal Energy Storage.” https://www.energy.gov/eere/buildings/thermal-energy-storage. 


\section{End-Use Needs}

Thermal loads within buildings can vary significantly across applications. Specific requirements for temperature levels and delivery methods mean that multiple technology approaches will likely be required to meet the storage needs across different end uses and building types. Understanding the distinctive needs and limitations of equipment-based storage technologies as well as envelope-embedded storage media will be critical to developing research activities to promote market adoption. The workshop encouraged participants to discuss technology pathways to further develop end-use-specific TES systems. 


\section{Workshop Structure}

The workshop engaged attendees in five primary ways. Keynote speakers provided background information on the challenges and opportunities surrounding TES, helping to set a common basis of understanding for the attendees. Next, moderated panel discussions allowed for deeper discussion into topics of importance to the workshop objectives through presentations from topic experts and interactions via questions and answer sessions. The attendees were then split into smaller groups to allow for deeper discussion during breakout sessions. Attendees were given opportunities for open discussion via a session at the end of each day and continuous engagement via the online chat functions of the virtual workshop. Finally, an electronic survey was distributed to all workshop registrants for additional information gathering.

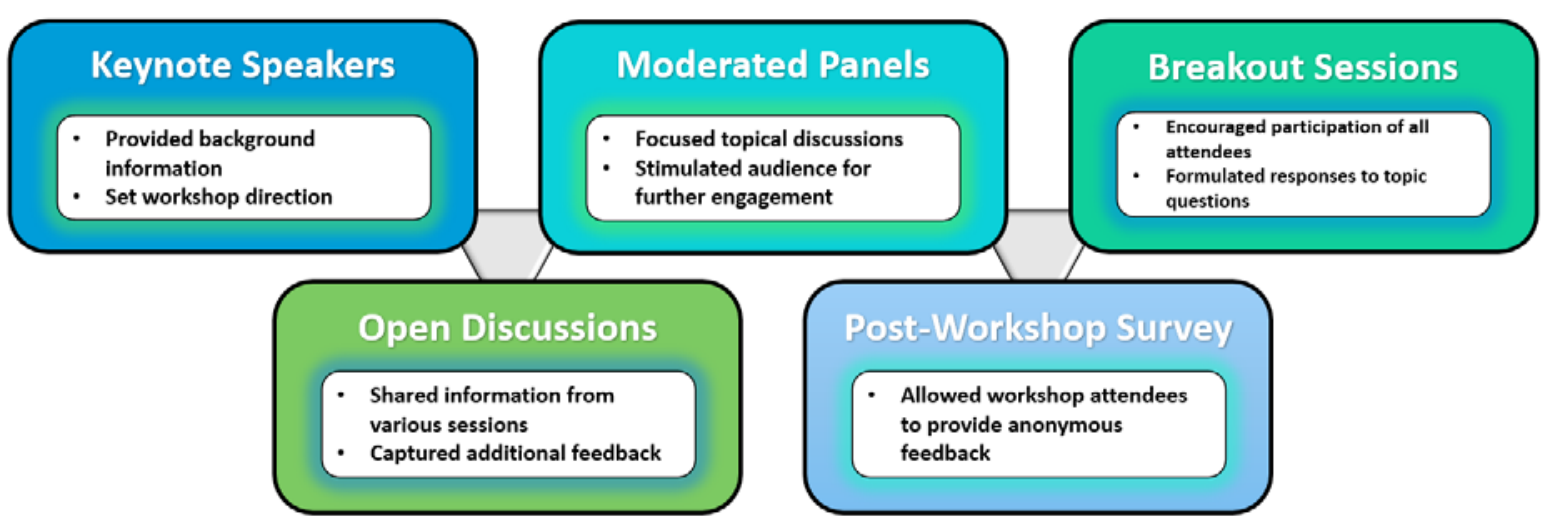

Figure 4. Workshop design 


\section{Participants}

Workshop organizers publicized the event on multiple online platforms and marketed it as free and open to the public. Targeted invites were also sent to individuals with specific experience that the organizers felt would be beneficial to the workshop objectives. A total of 617 individuals joined the workshop, with 554 attendees joining for the first day and 436 participants logging in for the second day. The workshop served a diverse, international audience, with 74 participants hailing from outside of the United States. Workshop registrants had backgrounds in numerous areas, as shown in Figure 5.
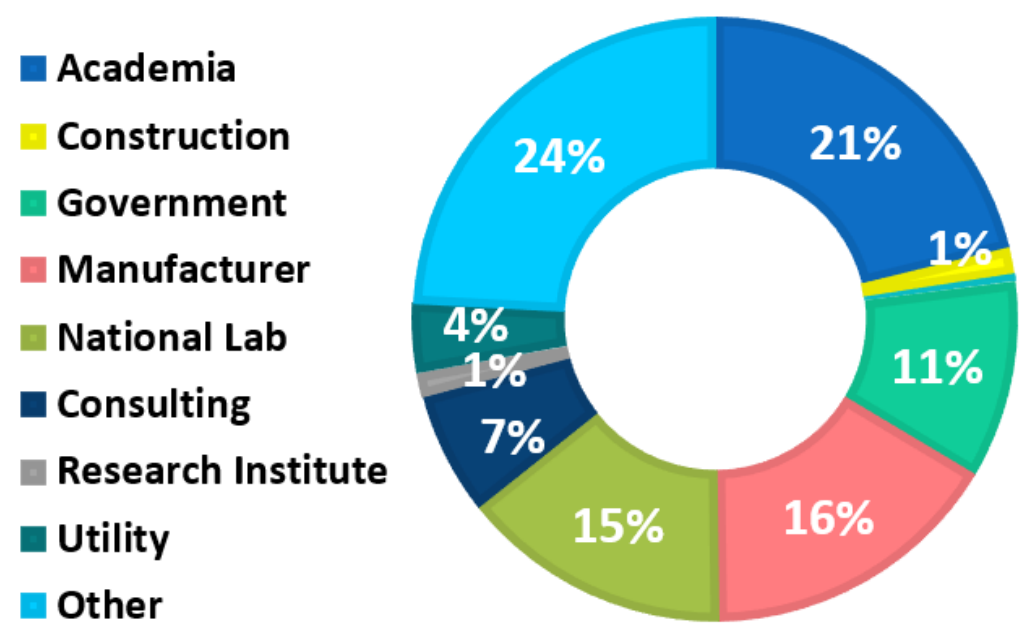

Figure 5. Breakdown of workshop registrants 


\section{Keynotes}

To kick off the first day of the workshop, Sven Mumme (BTO Technology Manager) presented an overview of the workshop objectives and goals. Peter Green (NREL Deputy Laboratory Director) then provided welcoming remarks and gave an overview of NREL's work enabling future energy transitions.

The first keynote presentation was given by David Nemtzow (BTO Director). Nemtzow began his presentation by discussing the climate goals of the Executive Branch and DOE. He then highlighted the magnitude of building energy consumption, including electrical and peak electrical usage, $\mathrm{CO}_{2}$ emissions, and utility costs in comparison to total U.S. energy usage. The challenges of finding solutions for the building sector were placed into context next to the complex and diverse nature of the U.S. building stock. Nemtzow stressed the importance of decarbonizing the building sector to achieve desired carbon emission reduction goals and the important role that renewable energy deployment, energy storage, and electrification can play toward this end (see Figure 6). He explained how thermal end uses drive peak demands in buildings, and how low-cost, long-life, high-efficiency TES could reduce waste and provide benefits to all communities. He explained the importance of time-sensitive valuation to extract increased value from TES systems, and discussed emerging technologies being developed with funding from BTO, including TES-integrated equipment and tunable storage technologies.

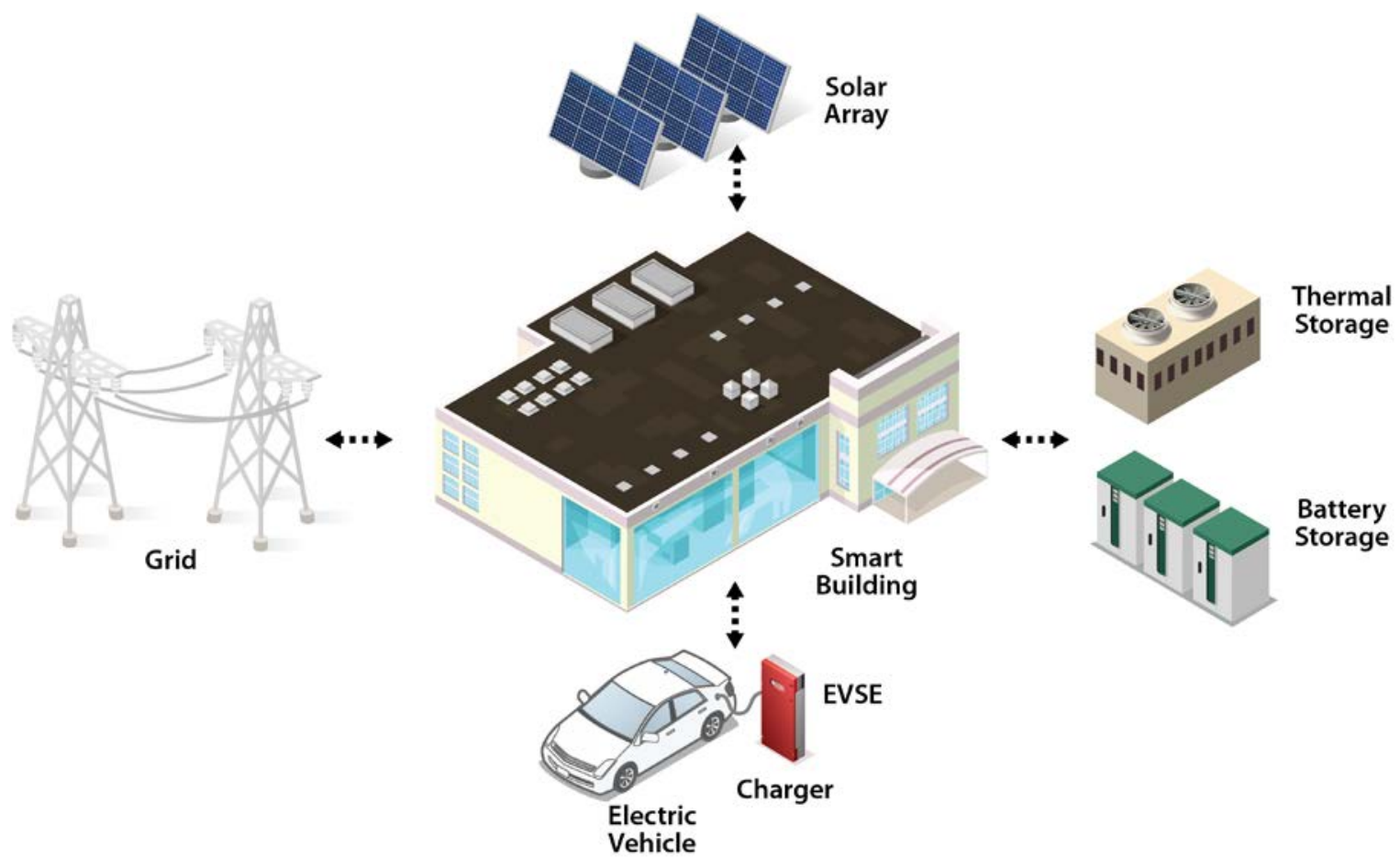

Figure 6. Depiction of a grid-interactive integrated energy ecosystem harnessing energy storage, renewable generation, and electric vehicle charging

Figure by NREL. Note that EVSE stands for electric vehicle supply equipment. 
The next keynote presentation was given by Mark MacCracken (Calmac-TRANE Vice President) on the topic of barriers to TES in buildings. MacCracken began by explaining that electrochemical batteries typically dominate the conversation around energy storage even though thermally based storage techniques can be dramatically cheaper. A major driver that he identified behind future TES growth is the electrification of heating in buildings. Benefits of TES include lower costs than electrochemical alternatives, sustainability of component materials, system reliability, and enabling load flexibility. He emphasized that TES and batteries should not be looked at as competitors but rather complementary solutions because each brings different services to the building. MacCracken then gave a brief history of the motivations for TES in buildings. In terms of the biggest barriers to TES, he presented on how the true value of TES in comparison to other technologies may not be accurately captured without a clear understanding of site versus source energy usage and the time value of energy. Additionally, the sale of TES can be complex because there are multiple individuals that influence whether a project is undertaken. These include building owners, developers, architects, engineers, contractors, and building operators. If any of these players do not fully understand their value, projects will not move forward. Customer education is a key strategy to overcoming some of these barriers. Solutions to TES deployment barriers can include simplified EnergyPlus ${ }^{\circledR}$ modeling and TES optimization in electrified buildings, promotional support from organizations such as DOE, and educational support for utility, regulator, and building industry stakeholders.

On the second day of the workshop, Dr. Andreas Hauer (ZAE Bayern Chairman of the Board) presented a keynote on the future vision of TES. He began by elaborating on the impact that thermal processes have on $\mathrm{CO}_{2}$ emissions, and highlighted TES as an appealing tool to help integrate increasing variable renewable energy sources. He presented a system-based approach, which incorporates a source, the storage medium, and the consumer. This includes various combinations of conversions between heat and power. Hauer presented various applications of TES, including waste heat utilization, concentrating solar power, cooling applications, and Carnot batteries. He then presented an economic analysis using a top-down approach on the maximum acceptable storage costs for these systems to be adopted in buildings. This analysis incorporated payback times, interest rates, and energy costs. Based on assumptions for payback times for different sectors and then users, Hauer presented on acceptable storage capacity costs as a function of storage utilization for TES in buildings and other sectors. 


\section{Moderated Panels}

For each panel discussion, the panelists were given five minutes to present. After all presentations concluded, the moderator would ask questions of the panelist as time permitted. Workshop attendees had the opportunity to submit written questions via chat functions for the moderator to pose to the panelists.

\section{The Big Picture: Opportunities for Thermal Energy Storage in Buildings}

The first panel of the workshop was moderated by Dr. Ravi Prasher of LBNL. He highlighted the role that TES can play in the building sector, and introduced the following panelists:

- Alejandro Moreno of the Office of Energy Efficiency and Renewable Energy (EERE) provided DOE's vision for clean energy goals. Moreno stressed the role storage (electrochemical, thermal, and chemical) can play in facilitating grid and building decarbonization, serving remote communities, promoting electrified mobility, and providing facility flexibility, efficiency, and value enhancement. He highlighted the DOE-supported ongoing research activities in TES and stressed the unifying efforts across technologies and functions from various DOE offices to carry out research, development, demonstration, and deployment of innovative technologies, systems, and practices that will put the United States on an irreversible path to achieve a carbon-free electricity sector by 2035 and achieve a $100 \%$ clean energy economy with net-zero emissions no later than 2050.

- Prof. Luisa F. Cabeza, from Universitat de Lleida, presented on the role of TES in the building sector, its current state of the art, and areas for improvement. Benefits that Cabeza highlighted of TES in buildings included reducing energy demand, increasing appliance efficiency and reuse of waste heat, and increasing the usage of renewable energy. The importance of educating consumers on the benefits of TES was stressed to increase acceptance of these technologies. Barriers to TES adoption were presented, including low TRL, high costs, and a general lack of knowledge of their benefits. Cabeza underlined the ongoing research activities on TES in Europe and the role the industrial sector played in its development and deployment. Research needs were highlighted at scales ranging through material development, component design, and system design. Additionally, Cabeza explained that it will be important to explore societal changes to better promote TES adoption.

- Dr. Claus Daniel, from Carrier, provided industrial perspective on the role of TES, as Carrier is a world leader in heating, ventilating, and air conditioning (HVAC); refrigeration; fire; and security solutions. Daniel emphasized that TES solutions can shift the electricity consumption from peak to off-peak hours and can make buildings smartgrid-ready by regulating equipment to respond to the peak electricity alerts on the power grid. A deployment in France where Carrier installed a complete chiller coupled TES system was given as an example of the potential of TES to reduce peak demand and allow for the reduction of chiller capacity requirements. The project had a return on investment of under 3 years.

- Ram Narayanamurthy, a Program Manager with the Electric Power Research Institute, emphasized that building electrification will increase the value of storage in distribution 
systems, and we need an approach to building decarbonization that leverages efficiency, flexibility, renewables, and electrification as tools to achieve customer-centric, lowcarbon, and affordable energy systems. Narayanamurthy discussed emergent TES technologies in the form of modular heat batteries from Sunamp and modular building construction materials with embedded phase change materials (PCMs). He also presented community-scale deployment examples of TES in Ontario, California ( 80 homes), and Fresno, California (60 homes), where thermal storage using hot water with $\mathrm{CO}_{2}$ heat pumps provided significant benefits to the occupants in the form of lower occupant bills, lower property owner costs, and significant carbon reduction.

\section{Application Value Drivers and Market Barriers}

The second panel of the workshop was moderated by Dr. Roderick Jackson of NREL. He gave an overview of the panel objectives to better understand the value propositions of TES and what barriers these technologies face in the market. Then he introduced the following panelists:

- Paul Steffes, of Steffes LLC, introduced his company's vison and solutions for TES. He presented the ability of aggregated TES resources to follow real-time solar outputs to absorb excess solar capacity. Steffes then presented three principles to ensure TES brings value to the grid and building owners/operators: being able to consume energy in real time, ensuring occupant comfort, and providing visibility and verification. Barriers to deployment that Steffes identified include communication reliability, security, and costs, as well as suitable electricity rate structures, rebates, and other incentives to facilitate adoption.

- Dr. Said Al-Hallaj, of NETenergy, highlighted how space cooling can drive utility charges in buildings. He then introduced NETenergy's TES solution for space cooling and elaborated on the value that it could provide to buildings, including estimates for peak load shaving and emission reduction potential.

- Dr. Reyad Sawafta, of Phase Change Solutions, began his presentation by discussing temperature control in a variety of industries and sectors including the built environment. He presented on his company's work using phase change materials as smart thermal mass, and the benefits these materials can provide for buildings - peak load reduction, resilience, and improving the integration of renewables. Market barriers include material challenges such as flammability and corrosiveness, low thermal conductivity and energy densities, and the need for price reductions.

- William Edrich, of Sunamp, shared information on Sunamp's storage solutions. The value propositions for TES that he identified include demand shifting to support both the electricity and gas grids, capturing surplus renewable generation, improving buildingand system-level efficiency, and increasing resilience. He discussed multiple market barriers including disconnects between who shoulders the costs of TES and who reaps the benefits, costs barriers, lack of familiarity and educational awareness among end users, the challenge of disrupting existing supply chains with new products, and the lack of a certification structure or product standard for TES.

- Pradeep Vitta, of Southern Company, provided a utility perspective to behind-the-meter TES. He began by discussing the value propositions of energy storage from utility and retail perspectives. Utilities are concerned with issues such as peak load management, 
increasing electrification, and grid and carbon resource management. Retail customers want to lower demand charges, better manage on-site renewable generation, and optimize HVAC equipment. Some barriers Vitta identified include high capital costs, the need for custom design and deep retrofits, space constraints, and integration with grid signals.

- Dr. Juan Catano, of Emerson, discussed numerous value drivers for TES technologies in buildings. These include the ability to provide flexibility at multiple levels by system sizing and control strategies, providing seamless technology transitions by requiring little to no behavioral changes to maintain comfort, and benefiting multiple stakeholders. Such benefits include lowering operating costs, reducing generation capacity requirements and transmission upgrades, and improving resilience. Market barriers Catano identified include communicating the value propositions to all stakeholders, improving customer perception of cost, efficiency, and complexity, and improving utilization across seasons.

\section{Demonstration, Technology Scaling, and Getting to the Field}

The third moderated panel also took place on the second day of the workshop. BTO's Cedar Blazek served as the panel moderator. Blazek introduced each of the panelists and explained the panel's objective of discussing the experience of deploying TES technologies, including challenges with integration, scaling, and getting building owners to adopt these technologies.

- Tapan Patel, of the Construction Engineering Research Laboratory, presented his work on PCM integration. His team retrofitted the attic of a Fort Bragg, North Carolina, classroom facility with insulation and PCM. The insulation reduced the temperature swings observed in the attic, and the PCM delayed the daily peak temperatures. Ultimately, Patel's company found that the facility used more energy with the passive PCM retrofit, and the microencapsulated PCM they used experienced degradation over time. Specific challenges he identified include the need for better modeling capabilities to select PCMs with high utilization for passive applications, as well as research on cycling to extend PCM lifetimes.

- John Andrepont, of The Cool Solutions Company, discussed the applications of TES in the context of district energy systems. An advantage of coupling TES with district energy systems is that they typically have more space available for the installation of large thermal storage capacities. Andrepont mentioned that some of the best opportunities for TES arise when the user is faced with a necessary near-term capital investment in thermal capacity. The application of TES to district systems also has the potential of avoiding negotiating with multiple building owners, operators, and architects, which can streamline deployment.

- Peter Horwath, of Insolcorp, presented on some of Insolcorp's thermal storage solutions, including PCM ceiling panels. These panels improve the thermal mass of the building to help the entire building serve as an energy storage system. Horwath explained that these systems are relatively easy to install and can provide notable energy savings and improved comfort. Additionally, he discussed ventilation-air-based storage systems and water-loop-based storage systems.

- Geoff Wickes, of the Northwest Energy Efficiency Alliance, shared expertise on gridenabled water heaters for TES. Wickes studied the impacts of water heater curtailments on customer satisfaction and found that customers were generally unaffected by the 
events. The study investigated both heat pump water heaters and electric resistance water heaters. Most of the study participants claim that they would partake in a similar demand response program in the future. Grid-enabled water heaters provide several value propositions for utilities, manufacturers, aggregators, and others. Barriers Wickes identified include increased capital costs, privacy security, and lack of awareness.

- Tom Vega, of the Baltimore Aircoil Company, discussed his experiences with ice storage equipment. Vega explained the differences between major ice storage equipment types and where they are typically installed. Most buildings that utilize ice storage typically have eight or more hours of reduced cooling load at night to allow the system to recharge. Common motivators for the adoption of ice storage technologies include the presence of variable utility rates, incentive rewards, boosting resilience, and downsizing equipment. Vega identified several challenges to deploying ice storage, including lack of space and familiarity with systems, flat utility rates, and complex incentive requirements with uncertain durations.

- Dr. Wim van Helden, of the AEE Institute for Sustainable Technologies, provided examples and status updates on compact TES systems. Van Helden described thermochemical materials that were utilized for near or no-loss long-term storage. AEE demonstrated a salt hydrate-based storage system in a home. Over the course of their study, AEE reported that they successfully provided heating with essentially no degradations in the storage materials. Van Helden then discussed some of the international collaborations taking place in the International Energy Agency on PCM and thermochemical material storage. He concluded his presentation discussing the future of compact TES including the driving influence of electrification and the need for long-term R\&D.

\section{Novel Systems and Approaches}

The final panel of the workshop was moderated by BTO's Erika Gupta. This panel was structured to discuss the next generation of TES technologies. Gupta introduced the panelists and moderated discussion with the audience.

- Dr. Jason Woods, of NREL, introduced NREL's multiscale thermal storage research consisting of modeling, design, and experimentation in materials, components, systems, and building grid integration. Woods then discussed opportunities for optimizing hybrid battery and thermal storage systems. He explained how hybrid systems could provide cost-optimal solutions through minimizing battery cycles and extending system lifetime.

- Dr. Som Shrestha, of ORNL, introduced an integrated thermally anisotropic building envelope concept. The benefits of the proposed technology include the redirection of heat in lieu of increased insulation, the potential to harvest thermal energy, and the ability to reduce HVAC loads providing demand reduction. Shrestha also presented results from field validations demonstrating the technology's abilities to redirect thermal loads.

- Dr. Sumanjeet Kaur, of LBNL, discussed her work on dynamic and tunable thermal storage. Distributing thermal storage in the building envelope takes advantage of the large surface area and volume of the envelope. By developing dynamic methods to 
modify transition temperatures and thermal resistances between the storage medium and its surroundings, the low utilization rates of passive PCM can be overcome.

- Dr. Mitchell Ishmael, of Active Energy Systems, presented his work on icephobic heat exchange for efficient, resilient building cooling. Active Energy Systems developed an icephobic heat exchange surface to stop freezing water from sticking to cold surfaces. This in turn allows for a small, low-cost heat exchanger with improved energy efficiency, reduced storage cost, and extremely high discharge capability.

- Joanne Huang, of OtherLab, introduced her work on developing TES using sensible storage mediums. This modular solution bundles tanks together to minimize standby losses and allow for more flexible use of space. The integrated solution aims to be low cost, increase efficiency, and even be accessible to low-income communities.

- Dr. Louis Desgrosseilliers, of Neothermal Energy Storage, introduced a supplemental electric thermal storage device using salt hydrate/water mixture to electrify residential furnaces and boilers. The concept supplies heat directly to the furnace return duct, automatically regulates heat delivery with the furnace/boiler, and has an automated demand response controller. Desgrosseilliers discussed the thermodynamic principles behind the storage medium and the performance benefits that it could provide to Canadian homes.

- Dr. Pim Donkers, of Cellcius, presented on a heat battery using thermochemical storage materials. The battery used a thermochemical material composite in a low pressure "closed-loop" with four components: evaporator/condenser, ventilator, heat exchanger, and reactor. The concept has the potential to be a heat battery with high energy density and no heat loss during the storage period. Additionally, it may provide an affordable, compact, robust, versatile, and sustainable design for energy storage.

- Dr. Matthew Aguayo, of EnKoat, discussed an envelope-based TES approach. EnKoat's Active Insulation is applied like normal construction paint, stucco, and plaster. The PCM embedded layers help reduce temperature swings within the building. EnKoat's solution can reduce the carbon footprint of the building, save money on heating and cooling costs, and shift peak load to off-peak hours.

- Arlene Anderson, of the U.S. Department of Energy Geothermal Technologies Office, presented on the potential of geothermal heat pumps, direct use of geothermal heat, and TES to save energy and shift loads. Reservoir TES was discussed as having the potential to provide seasonal storage for heating and cooling needs. Additionally, Anderson discussed work on a hybrid concept using geothermal devices incorporating PCMs. 


\section{Breakout Session and Discussion Structure}

Based on their preferences upon registration, participants were assigned into one of three breakout topics during the first day of the workshop:

- Adoption and Deployment Barriers

- System Cost, Performance, and Market Requirements

- Key Applications and Value Drivers.

For the second day of the workshop, participants were assigned to one of four breakout session topics covering specific end uses for TES technologies in buildings:

- Space Cooling

- Space and Water Heating

- Refrigeration

- Envelope Embedded Storage.

To allow for smaller group discussions, each track was divided into two groups. Facilitators guided discussion in each breakout group with questions from the workshop organizing committee. During the breakout session, attendees had the option to engage with each other through verbal discussion or written commentary. At the end of the breakout session, facilitators presented highlights of the group discussions to the entire workshop audience. After a summary was given from each breakout group, an open discussion question-and-answer session was held to garner more feedback from the audience based on the topics that were discussed. 


\section{Breakout Session Summaries}

The breakout session discussions each day lasted for approximately one hour. Each session contained at least one facilitator and a notetaker selected by the organizing committee. Each facilitator was given a list of questions to help spur and guide discussion. There was no prescriptive guidance given regarding how long each breakout session should spend on discussing each question. The flow of the conversation was left to the facilitator's discretion. Following are summaries of the feedback generated from the breakout discussions. 


\section{Adoption and Deployment Barriers}

\section{Technical}

- Constraints on volume and weight, for example in the case of packaged systems like rooftop units and split systems.

- Integrating TES systems with existing building controls or with utility controls. Additionally, integrating TES with existing systems may lead to the invalidation of original system warranties.

- Need improved analysis to provide a clearer picture of the potential and limits of TES to communicate to electric/gas utilities.

- Simplified modeling would make designing thermal storage systems easier. Modeling for sales is also important to convey value to stakeholders.

- There are currently no good estimates of the costs related to installation, operation, and recycling or disposal of TES systems. Additionally, there are currently no cost targets that researchers or developers can aim for in the future development of this technology.

- PCM measurements have been unreliable because the measured values vary based on the measurement techniques. Developing reliable measurement methods are as important as the material development.

- TES durability has not been widely studied for many storage materials. It has been reported that many PCMs are sensitive to water, moisture, UV light, corrosion, etc., and that needs to be thoroughly investigated and understood. Other aspects like cyclability, life cycle analysis, and fire and health hazard should also be considered.

\section{Educational}

- More work is needed on educating policy makers on benefits and appropriate metrics for TES.

- The uniqueness of TES needs to be better understood. It is treated as electrical storage when it should be judged on its own terms.

- Stakeholders - including architects, building owners, equipment installers, and othersneed to be made aware of the possibilities of incorporating TES in buildings.

\section{Financial}

- TES has significant upfront capital expense, and little to no third-party/middle entity to fund the capital costs.

- Need value propositions for residential and commercial buildings, as well as for homeowners, building owners, and utilities. 
- Customers want fast paybacks, while utilities are avoiding long-term investments. TES solutions need to meet needs of all stakeholders.

\section{Standards Development}

- Standard protocols are needed for testing and comparing TES systems to each other as well as comparing TES to other types of energy storage.

- Wide variation in building codes can be a barrier to new technology implementation.

- Codes and standards will need to be updated, or new ones developed, to capture TES. AHRI 900 is used for TES equipment but is not as well known by the HVAC industry and typically applies only to large equipment.

- There is also a need for a standard communication protocol between the TES equipment and the electric utility or the DR aggregator. This is exacerbated by the fragmented HVAC market, with each manufacturer having their own proprietary controller.

- Lacking codes and standards related to TES-integrated buildings means there is no authoritative document to guide builders/contractors to follow certain procedures.

\section{Policy}

- There is no clear value proposition for residential TES. Infrastructure for financial, legal incentives have not been worked out.

- Many policy makers do not know that TES can enhance air-source heat pumps. Regulatory mandates should be explored for TES.

- Building standards may need to evolve to credit thermal storage.

- Rebates and other offerings can be used to encourage more decision makers to consider TES in buildings.

- It seems current consortiums are focused on electrical storage only. The TES industry should organize to present their case to regulators and policy makers.

\section{Workforce}

- There is a lack of infrastructure to support O\&M requirements and support services. There is also uncertainty surrounding maintenance requirements.

- Incumbent HVAC contractors and energy service companies are often resistant to change.

- A robust manufacturing, installer, and maintenance provider base will be needed to support increased deployment. 
- Knowledgeable operators are needed for some storage operation. In Arizona there are TES systems that have been abandoned because of a lack of professionals to run them.

\section{Technology Transfer}

- Scaling up is difficult when manufacturing and designing new products.

- Funding is needed to bridge the gap between research systems and deployment demonstrations. Improved transfer of novel benchtop concepts to a larger scale can help in achieving market penetration.

- DOE, national labs, and research institutions can help accelerate the rate at which research gets out of the lab and into the market.

\section{Partnerships to Overcome Barriers}

- NYSERDA have initiatives on district heating that could be approached to incorporate TES and used as a model for future initiatives.

- Professional associations like ASHRAE and the U.S. Green Building Council can take a leading role in educating their members on the value of TES.

- Partnerships with original equipment manufacturers could be formed to promote product offerings for TES and look at ways to standardize the assessment of performance characteristics.

- Technical Assistance Partnerships (TAP) could help with communicating the value proposition and opportunities of TES to building owners/operators/etc.

- Proposing TES deployment as a part of a more general community economic development initiative would be helpful, where access to new technology is being broadened.

- We need more intersectional conversations between people in the technical space and those in the real estate and housing sector.

- Community colleges that have HVAC training could incorporate TES into their curriculum. 


\section{System Cost, Performance, and Market Requirements}

\section{System Costs Reduction}

- We need low-cost materials with desirable thermal properties. It may be necessary to work with materials that are $\$ 2 / \mathrm{kWh}$ or less.

- Passive solutions in buildings materials are less common but may be lower-cost solutions.

- There is a divide between system-level people and academics. What costs should material scientists achieve? This information could inform research directions.

- A better understanding is needed of how to equally distribute both costs and value of TES to different stakeholders (e.g., utilities, building owners, HVAC manufacturers, HVAC contractors).

- To provide TES for low- and moderate-income households, we must find a way to provide third-party ownership in the form of leases, power-purchase agreements, sharethe-savings, or similar. Low- and moderate-income households are capital limited but can often produce revenue flows high enough to satisfy needs of capital providers.

- Integrating TES into equipment at the factory can minimize custom engineering costs and installation costs at the building site. Field installation is also acceptable, but it should be standardized as much as possible to minimize engineering and installation cost.

- It would be beneficial if cooling TES could also be used for heating in the winter, as this would increase the benefit/cost savings for a single asset, improving the economics.

- There is a cost to determining the correct size of the TES and cooling system, and in showing the building owner how much it will save. Better tools could reduce this cost. This could also involve design guides and rules of thumb that improve intuition of designers and help them specify these TES systems.

- The supply chain for custom components is expensive. Although the commercial and industrial markets often require custom components, the residential sector typically does not. Statistical studies of the needs of different house styles, size, etc. can be done, which could lead to building a product that will have a market potential of millions of units without customization, even while ignoring many other kinds of homes.

- We can take lessons from the solar industry, which also started out as a small-scale fragmented industry. Rather than require building owners to cover the entire upfront costs of systems, the industry got access to capital by third-party financing and structures like power purchase agreements. We can replicate something like NREL's Solar Access to Public Capital Working Group for the HVAC sector. 
- Providing zoned HVAC/TES solutions to a confined room or area of a building may be a lower-cost solution to bring some degree of comfort to low-income populations.

\section{System Performance}

- Full control is needed over when/how TES charges and discharges.

- Heat pump performance can vary with ambient conditions. With proper controls, TES can provide efficiency improvements if heat pump lifts are high during peak demand periods.

- Material improvements and heat transfer enhancements may be required to provide high power delivery. Heat transfer into and out of the TES material is critical, which is typically a more expensive part of the TES system than the material alone.

- Building thermal end uses can utilize heat over a wide range of temperatures. As many TES systems are designed to deliver heat at a specific temperature range, it will be important to understand the temperature levels needed for a particular application.

- The lifetime and degree of performance degradation of thermal energy storage materials can vary. Understanding how long and how frequently a storage asset can be utilized will be important for assessing the economics of a TES system.

- Quantify the degree to which the storage asset can support grid stability and resilience.

- Understanding the risk and hazards to property and personnel should the storage system undergo unexpected failure.

- Being able to predict availability for optimized control is important, including real-time measurement and control, as well as model predictive control to minimize economic cost.

\section{Market Requirements}

- Need to better understand what type of rate structure and billing rate would make the system beneficial.

- Need to better understand how TES will help avoid expanding generation capacity and transmission and distribution networks.

- We need to take life cycle analysis tools from research to application. Modeling of these systems is difficult and can help support economic incentives beyond demand reduction.

- Ideally, TES would not require sacrifices for other parts of the building design. For example, if adding TES makes the engineer's job more difficult or risky, or it means there is more work to coordinate with other aspects of the building design, it will make them less likely to design TES for that building. 
- There are several kinds of customers each with needs that must be addressed. For instance, manufactures would be worried if they must set up a new manufacturing process; buildings/installers/contactors are concerned about the litigation due to poor workmanship; and homeowners are sensitive to the installation and operational costs.

- NREL and other labs have come up with standard criteria in the past to help people quantify clean energy tech (source energy multipliers, health consequences of certain emissions, etc.). One useful thing could be a quantifier for cost savings that we do beyond energy savings. 


\section{Key Applications and Value Drivers}

\section{Deployment Prioritizations}

- We need to address the basic question of when in the sequence of grid-interactive efficient building measures do we implement TES? What is the priority of TES for single-family buildings, commercial buildings, city-scale multifamily buildings, etc.?

- Markets with high renewable energy penetrations are likely to see larger variations in costs, and therefore would make them more suitable to have good payback.

- Rooftop units can be found on commercial buildings of various sizes. The large size of the market for this equipment makes them attractive candidates for integrating with TES to spur rapid deployment.

- The high utilization rates of refrigeration system can make them appealing candidates for TES because they have large loads that persist most of the time.

- There could be some research focused on how to integrate TES into public housing. Centralized ownership makes this an attractive target for market entry.

- When installed with new construction, the higher upfront cost of TES could be amortized into a mortgage on a new building purchase.

- Space is a general requirement for many TES applications. Buildings and facilities with ample space should be targeted for early adoption.

- Because there are several methods to include TES in buildings, a "TES selector" tool can help the installers choose the appropriate solution and make an informed decision without knowing the in-depth technical specifications of each technology.

\section{Storage Durations}

- Sensible TES materials are likely to be utilized for sub-hourly durations due to their limited storage capacity. Exceptions occur when sufficient volume is available to house large storage media.

- Durations ranging from 1-8 hours can be provided by phase change and thermochemical materials at higher energy densities than sensible storage methods. Different durations needs may arise between heating and cooling applications as they tend to have different peak profiles throughout the day.

- Seasonal energy storage can vastly increase the utilization of variable renewable generation. Certain TES materials, such as thermal chemical reactions, can store heat for long durations with minimal losses. 


\section{Incentives}

- Drivers must be long term. In the past ( 1986), TES incentives did not last, and this turned the market and investors off.

- Encourage architecture and engineering firms to consider TES in their bids. This could be LEED points, or something else.

\section{TES Value Drivers}

- We need to identify rate structures that lead to beneficial value; categorization framework and metrics around different applications are needed as well.

- Electrical service upgrade costs could be avoided when switching from gas to heat pumps if the heat pump includes storage.

- TES can help increase system capacity without upgrading chiller plant equipment.

- TES can provide prolonged comfort for building occupants in the event of power outages or other grid interruptions.

- When coupled with refrigeration systems, TES can help maintain temperatures for food and medical supplies during power outages, thus reducing spoilage.

- TES increases the value of DERs by reducing energy usage required to maintain thermal comfort.

- As the grid composition and time-of-use charges evolve, a better understanding of the value of TES considering various scenarios will be important. This will require connecting grid, building, and TES models for system-level analysis. EnergyPlus and other modeling platforms should integrate TES and advanced HVAC technology, as well as utility rates to easily showcase the value drivers to the stakeholders. 


\section{Additional Technology Considerations}

\section{Comparisons to Li-lon Batteries}

- A challenge with electrical batteries is that from a distribution planning perspective, they add to the load. TES has the potential to boost efficiency, which could permanently reduce the load.

- TES may have safety benefits compared to electrochemical storage solutions.

- End-of-life recycling of TES systems may be easier than that for electrical batteries. We should consider embedded energy used for the different technologies.

\section{Installation and Integration}

- Features such as self-diagnostics during installation can ensure proper installation, even if the installer is not familiar with TES.

- The goal is not about making TES better, but about making the overall systems better. Focus on system-level solutions would be preferred rather than standalone systems.

- Integration should consider existing resources such as waste heat sources and existing thermal mass to maximize benefits.

\section{Lifetime and Operation Impacts}

- TES systems will inevitably change the duty cycle for heating and cooling equipment operation. What is the inherent lifetime and maintenance costs of TES technologies and how will they impact the lifetime and O\&M costs of other building equipment and systems?

- Research institutions should publish how to determine the carbon footprint and embodied carbon impacts of TES in buildings. This could help when approaching users that are environmentally minded.

\section{Manufacturing}

- It would also help architects and engineers if TES were a standard packaged option from manufacturers. An example would be the engineer would specify the building type and climate in some tool, and it would suggest a model number for the HVAC + TES system that should be installed in that building.

- We cannot forget about manufactured housing and trailers. These facilities do not stick around for as long as other housing options, and they tend to use more heating and cooling relative to their size. 
- Deploying low-cost envelope-embedded or geothermal methods can help make up for lower energy density TES.

\section{Non-Energy Benefits}

- Energy bills are a minor fraction of the operational costs of some commercial buildings. This can make for slower adoption when proposing technologies with purely energy efficiency benefits.

- The impact that new technologies have on occupant comfort as well as indoor air quality improvements are typically underrepresented. Efforts should be taken to better quantify the influence of TES on these metrics.

\section{Sensors and Controls}

- Smart building automation systems will be required to ensure that TES technologies sync with other building systems and do not needlessly waste energy.

- Controls are particularly important for thermal storage systems, as there are now two objectives: keep occupants comfortable (like other AC systems) and provide some load shaving, shifting, etc.

- Continuous commissioning may be required to ensure correct operation over time. Controls also may need to change depending on the utility's needs or rate structure.

- Improved analytics including machine learning and AI are needed to better manage the loads and impact the grid.

- Accurate accounting of system state of charge is needed, as well as communication back to the grid operation on the state of charge.

- Optimizing heat pump controls for charging of TES could help us understand efficiency impacts of ambient conditions in addition to time-of-use rates.

\section{Stakeholder Confidence}

- Standardized methods are needed for certifying the performance and reliability of storage components and systems. Commissioning processes may be helpful in validating the nominal amount of energy and carbon savings of TES systems.

- Some of the technologies are still experimental. There are no design rules to help guide developers for practical applications.

- Simple models are needed for architects/engineers to understand the benefit of TES.

- There is a need for more defined and clear language in codes and standards to provide guidelines during installation and safe operation of TES systems in building envelopes. 
- Better understanding is needed on how TES can help downsize chillers boilers and other prime drivers for thermal management. Additionally, TES can reduce the number of different units needed to install, creating commonality in a building, and reducing maintenance costs.

- A market-driven approach to TES development would enable researchers to understand the customer needs and provide motivation to scale-up the material synthesis process while minimizing the cost.

\section{Utilization}

- Conventional PCMs have a fixed transition temperature that limits PCM utilization within a narrow operating temperature bound. Dynamically varying transition temperature using external excitations (e.g., electric/magnetic field or pressure) can make TES dynamic and responsive to the changing environment, thereby increasing TES utilization.

- Ventilation loads are going to be higher in the future, which will shift loads from sensible to more latent loads. TES must be able to handle dehumidification as well as sensible control.

\section{Understanding Value}

- It could be beneficial to have a dashboard and better tools integrated into the system to know how the TES is performing over time. This helps with operation, but also gives some visibility to both the engineer and the building owner.

- More people are becoming familiar with preconditioning to cool or heat buildings. This could be used as a springboard to expand openness to applications of other kinds of thermal storage. 


\section{Summary of Recommendations}

A consistent theme throughout the workshop was the development of a TES Consortium. This would allow the TES industry to organize and better present their case to regulators and policy makers. Additionally, close collaboration between researchers, original equipment manufacturers, builders, and utilities can ensure that solutions are best tailored to the needs of all stakeholders. For TES to succeed in the market, feedback from all the stakeholders is important and must be incorporated in the TES development process.

Additional key recommendations are listed below and are categorized by technical and nontechnical requirements.

\section{$\underline{\text { Technical }}$}

1. Codes and Standards: Develop codes and standards for TES in building applications with consistent performance measurement criteria. Dynamic performance standards are needed to capture the true benefits of storage-integrated systems.

2. Modeling: Improve modeling capabilities for assessing the potential of TES. Tools must be suitable for use by sales personnel and non-researchers. A "TES selector" tool can help the installers choose the appropriate solution and make an informed decision without knowing the in-depth technical specifications of each technology.

3. High Utilization Materials: Support high utilization materials, as buildings generally cannot use one TES system for all thermal end uses in a building because they are at different temperatures. Tunable and smart materials may change this paradigm.

4. Packaged Solutions: Design systems with installation in mind. Turnkey products with minimal on-site customization are preferred.

5. Material Costs Reduction: Prioritize lowering upfront capital cost. Low-cost materials with desirable thermal properties are needed.

6. Deployment Guidelines: Address the question of when in the sequence of gridinteractive efficient building measures we implement TES as well as how this varies by building type and location. Develop categorization framework and metrics around different applications. Identify rate structures that would lead to the greatest beneficial value.

7. Technology-to-Market: Accelerate the rate at which novel research is transitioned to manufacturers and deployed to the market.

8. Life Cycle Analysis: Take life cycle analysis tools from research to application. Modeling of these systems is difficult and can help support sales pitches beyond demand reduction. Incorporate embodied carbon and end-of-life characteristics to compare to other technologies.

9. Certification Process: Standardize certifying the performance and reliability of storage components and systems. Commissioning processes may be helpful in validating the nominal amount of energy and carbon savings of TES systems. 
10. Self-Diagnostics: Encourage such features during installation to ensure proper installation, even if the installer is not familiar with TES. Additionally, accurate accounting of system state of charge can aid in control optimization.

Non-Technical

1. Education: Work to educate policy makers and building owners on benefits and appropriate metrics for TES.

2. New Business Strategies: Encourage third-party financing for HVAC/thermal storage. Alternative market delivery mechanisms need to be developed and demonstrated.

3. Workforce Development: Support training for installation and maintenance. Reach out to community colleges and training programs. Additionally, outreach to architects and engineers in school can help educate future workforce.

4. Consistent Incentives: Give stakeholders some degree of certainty that incentives like utility rates to support deployment will last.

5. Technical Assistance Partnerships: Utilize these types of partnerships, particularly because understanding the value proposition and time-varying opportunities are more complicated for building owners and operators. A neutral organization can help disseminate information.

6. Community Ties: Propose TES deployment as a part of a more general community economic development initiative, where access to new technology is being broadened.

7. Regulatory Advocacy: DOE to consider working as a convener to formulate workable standards and mandates that could be enacted. 


\section{Appendix A. Workshop Agenda}

\section{U.S. Department of Energy Thermal Energy Storage Systems for Buildings Workshop}

Priorities and Pathways to Widespread Deployment of Thermal Energy Storage in Buildings Hosted by DOE's Building Technologies Office, National Renewable Energy Laboratory, Oak Ridge National Laboratory, and Lawrence Berkeley National Laboratory

\section{(Eastern Daylight Time)}

\begin{tabular}{|c|c|}
\hline \multicolumn{2}{|c|}{$\begin{array}{c}\text { Day } 1 \\
\text { May 11, 2021: Opportunities, Value Drivers, and Barriers for Thermal Energy Storage }\end{array}$} \\
\hline 11:00 AM - 11:03 AM & $\begin{array}{l}\text { Workshop Outline and Goals } \\
\text { Sven Mumme | DOE Building Technologies Office }\end{array}$ \\
\hline 11:03 AM - 11:10 AM & $\begin{array}{l}\text { Welcome and Opening Remarks } \\
\text { Peter Green | National Renewable Energy Laboratory }\end{array}$ \\
\hline 11:10 AM - 11:30 AM & $\begin{array}{l}\text { Keynote - Grid-Interactive Efficient Buildings and Thermal Energy Storage } \\
\text { David Nemtzow | DOE Building Technologies Office }\end{array}$ \\
\hline 11:30 AM - 12:30 PM & $\begin{array}{l}\text { Panel Discussion | The Big Picture: Opportunities for Thermal Energy Storage in } \\
\text { Buildings } \\
\text { (Moderated by Ravi Prasher | Lawrence Berkeley National Laboratory) } \\
\text { - Alejandro Moreno | DOE Office of Energy Efficiency \& Renewable Energy } \\
\text { - Luisa F. Cabeza | University of Lleida, Spain } \\
\text { - Claus Daniel | Carrier } \\
\text { - Ram Narayanamurthy | Electric Power Research Institute }\end{array}$ \\
\hline 12:30 PM - 1:00 PM & $\begin{array}{l}\text { Keynote Address - Barriers to Thermal Energy Storage in Buildings } \\
\text { Mark MacCracken I CALMAC Portfolio of Trane }\end{array}$ \\
\hline 01:00 PM - 01:10 PM & Break (with Fun Trivia, Polls, and Quizzes!) \\
\hline 01:10 PM - 02:25 PM & $\begin{array}{l}\text { Panel Discussion | Application Value Drivers and Market Barriers } \\
\text { (Moderated by Roderick Jackson | National Renewable Energy Laboratory) } \\
\text { - Paul Steffes | Steffes } \\
\text { - Said Al-Hallaj | NETenergy } \\
\text { - Reyad Sawafta | Phase Change Solutions } \\
\text { - William Edrich | Sunamp } \\
\text { - Pradeep Vitta | Southern Company } \\
\text { - Juan Catano | Emerson }\end{array}$ \\
\hline 02:25 PM - 02:30 PM & Introduction to Breakout Sessions \\
\hline 02:30 PM - 03:30 PM & $\begin{array}{l}\text { Concurrent Breakout Sessions } \\
\text { Breakout } 1 \text { - Adoption and Deployment Barriers } \\
\text { Breakout } 2 \text { - System Cost, Performance, and Market Requirements } \\
\text { Breakout } 3 \text { - Key Applications and Value Drivers }\end{array}$ \\
\hline
\end{tabular}




\begin{tabular}{|l|l|}
\hline 03:30 PM - 03:45 PM & Break (with Fun Trivia, Polls, and Quizzes!) \\
\hline 03:45 PM - 04:55 PM & Breakout Session Summaries for Roadmap Development \\
\hline 04:55 PM - 05:00 PM & $\begin{array}{l}\text { Day 1 Closing Remarks } \\
\text { Sven Mumme | DOE Building Technologies Office }\end{array}$ \\
\hline
\end{tabular}

\begin{tabular}{|c|c|}
\hline \multicolumn{2}{|c|}{$\begin{array}{c}\text { Day } 2 \\
\text { May 12, 2021: Technology Pathways to Market Adoption, Demonstration, Deployment }\end{array}$} \\
\hline 11:00 AM - 11:10 AM & $\begin{array}{l}\text { Welcome and Outline of Workshop Day } 2 \\
\text { Sven Mumme | DOE Building Technologies Office }\end{array}$ \\
\hline 11:10 AM - 11:40 AM & $\begin{array}{l}\text { Keynote Address - Future Vision of Thermal Energy Storage } \\
\text { Andreas Hauer | ZAE Bayern }\end{array}$ \\
\hline 11:40 AM - 12:40 AM & $\begin{array}{l}\text { Panel Discussion | Demonstration, Technology Scaling, and Getting to the Field } \\
\text { (Moderated by Cedar Blazek | DOE Building Technologies Office) } \\
\text { - John Andrepont | The Cool Solutions Company } \\
\text { - Tapan Patel | Construction Engineering Research Laboratory } \\
\text { - Peter Horwath | Isolcorp } \\
\text { - Teoff Wickes | Northwest Energy Efficiency Alliance } \\
\text { - Wim van / Baltimore Air Coil } \\
\end{array}$ \\
\hline 12:40 PM - 12:50 PM & Break (with Fun Trivia, Polls, and Quizzes!) \\
\hline 12:50 PM - 02:00 PM & $\begin{array}{l}\text { Panel Discussion | Novel Systems and Approaches } \\
\text { (Moderated by Erika Gupta | DOE Building Technologies Office) } \\
\text { - Jason Woods | National Renewable Energy Laboratory } \\
\text { - Som Shrestha | Oak Ridge National Laboratory } \\
\text { - Sumanjeet Kaur | Lawrence Berkeley National Laboratory } \\
\text { - } \quad \text { Jitchell Ishmael | Active Energy Systems } \\
\text { - Louis Desgrosseilliers | Neothermal } \\
\text { - Pim Donkers | Cellcius } \\
\text { - Matthew Aguayo | EnKoat } \\
\end{array}$ \\
\hline 02:00 PM - 02:10 PM & Introduction to Breakout Sessions \\
\hline 02:10 PM - 03:10 PM & $\begin{array}{l}\text { Concurrent Breakout Sessions | Sensible, Latent, Thermochemical Storage Solutions } \\
\text { Breakout } 1 \text { - Space Cooling } \\
\text { Breakout } 2 \text { - Space/Water Heating } \\
\text { Breakout } 3 \text { - Refrigeration } \\
\text { Breakout } 4 \text { - Envelope Embedded }\end{array}$ \\
\hline 03:10 PM - 03:25 PM & Break (with Fun Trivia, Polls, and Quizzes!) \\
\hline 03:25 PM - 04:20 PM & Breakout Session Summaries for Roadmap Development \\
\hline 04:20 PM - 04:30 PM & $\begin{array}{l}\text { Workshop Closing Remarks } \\
\text { Sven Mumme | DOE Building Technologies Office }\end{array}$ \\
\hline
\end{tabular}




\section{Appendix B. Presenter Biographies}

Presenter names that are underlined indicate hyperlinks with more information.

\section{Sven Mumme}

Sven Mumme is a technology manager in the Building Technologies Office (BTO) at the U.S. Department of Energy (DOE). He is the Emerging Technologies lead on Opaque Building Envelope and Thermal Energy Storage R\&D. Sven originally joined DOE in 2012 as an ARPA-E technology-to-market advisor, where he helped transition breakthrough energy technologies from lab to market.

\section{Peter Green}

Dr. Peter Green has served as deputy laboratory director for Science and Technology and chief research officer of NREL and senior vice president of the Alliance for Sustainable Energy-the company that operates NREL for the U.S. Department of Energy-since 2016. In his role as deputy laboratory director for Science and Technology, Green is responsible for NREL's science and research goals, strengthening the laboratory's core capabilities, and enhancing NREL's research portfolio.

\section{David Nemtzow}

David Nemtzow is the Building Technologies Office Director of the Office of Energy Efficiency and Renewable Energy (EERE). He previously served as the team's senior strategist. David brings to EERE more than three decades of experience in the industry, including running a large state government energy and water department, a prominent bipartisan nonprofit energy efficiency association, and an energy consulting practice.

\section{Ravi Prasher}

Dr. Ravi is the Associate Lab Director of the Energy Technologies Area and Interim Division Director of Cyclotron Road at Lawrence Berkeley National Laboratory (Berkeley Lab). He is also an adjunct professor in the Department of Mechanical Engineering at the University of California, Berkeley. Ravi has published more 90 archival journal papers in top science and engineering journals such as Nature Nanotechnology, Physical Review Letters and Journal of Heat Transfer. He holds more than 35 patents in the areas of thermoelectrics, microchannels, heat pipes, thermal interface materials, nanostructured materials, and devices.

\section{Alejandro Moreno}

Alejandro Moreno is the Acting Deputy Assistant Secretary for Renewable Power at the U.S. Department of Energy. He previously was the Director for the Department's Water Power Technologies Office, where he is responsible for the Department's R\&D portfolio for hydropower and marine renewable energy. Working with the DOE national laboratories, universities and industry, his team designs and funds innovative science and technologies to support renewable energy generation, power system reliability, and both freshwater and marine ecosystems. 


\section{Luisa F. Cabeza}

Dr. Luisa F. Cabeza is a full Professor of Thermal Engineering at the University of Lleida (Spain), where she leads an internationally recognized research group in thermal energy storage. Her research interests are thermal energy storage, energy efficiency and renewable energies, and buildings and industrial applications. Professor Cabeza is very active in working groups of the International Energy Agency, is the Thermal Storage Focus Leader of the Renewable Heating and Cooling European Platform and has participated in the Special Report on Renewable Energy of the IPCC and on its Fifth Assessment Report (AR5).

\section{Claus Daniel}

Dr. Claus Daniel leads Carrier's Strategic Innovation theme focused on sustainability with an increased focus on identifying opportunities and initiatives that lead to significant new products and services or disruption. He is responsible for developing a portfolio of initiatives in support of the strategy and overseeing the maturation and development of each initiative toward a transition to commercializable products or services. He joined Carrier from Oak Ridge National Laboratory, where he has held numerous leadership roles.

\section{Ram Narayanamurthy}

Ram Narayanamurthy is the technical lead and program manager for Advanced Buildings at EPRI. He directs research in the areas of Building Decarbonization, Building Flexibility and Smart, Sustainable and Resilient Communities. He has been instrumental in advancing California's goals for Net Zero Energy and zero carbon buildings, developing the first zero net energy neighborhood and developing zero energy affordable housing communities in the Central Valley and Southern California.

\section{$\underline{\text { Mark MacCracken }}$}

In November 2017, Mark MacCracken became the VP, CALMAC Portfolio for TRANE. Prior to CALMAC's purchase by TRANE, he was CEO of CALMAC, which is one of the largest manufacturers of Thermal Energy Storage equipment in the world, with over 4,500 installations in 60 countries. In his over 44 years in the energy storage field, he has assisted in the design of hundreds of ice storage systems around the world. Some of the larger installations in New York City were for Rockefeller Center, Credit Suisse, Google, Goldman Sachs, and the Bank of America Tower.

\section{Roderick Jackson}

Dr. Roderick Jackson is the laboratory program manager for buildings research at NREL. He sets the strategic agenda for NREL's buildings portfolio, while working closely with senior laboratory management. The portfolio includes all research, development, and market implementation activities, which aim to improve the energy efficiency of building materials and practices. Dr. Jackson comes to NREL from Oak Ridge National Laboratory, where he was the group manager for Building Envelope Systems Research. 


\section{Paul Steffes}

Paul Steffes is the Founder of Steffes LLC based in Dickinson ND, a manufacturer of Electric Thermal Storage equipment for load management and electric energy storage programs since 1987. Paul is a Professional Engineer who is responsible for many innovative solutions and is always open to new ones. He can share proven results from about 100,000 deployments that optimize various products providing visibility, controllability, and verification with a multitude of one- and two-way communication methods. Paul has always been on the cutting edge of thermal storage and has visions of how widespread deployment of thermal energy storage can deliver great benefit to the energy future of our nation.

\section{Said Al Hallaj}

Dr. Said Al-Hallaj is the co-Founder of All Cell Technologies LLC, a Li-ion battery manufacturing company, Founder and CEO of NETenergy, a thermal energy storage company, and a Research Professor of Chemical Engineering at the University of Illinois at Chicago. Said co-authored a book entitled "Hybrid Hydrogen Systems" and has published several book chapters and numerous numbers of peer reviewed and conference journal papers with $>10,000$ literature citations. Said is a serial entrepreneur, and his $R \& D$ effort has led to the successful commercialization of several clean-tech technologies.

\section{Reyad Sawafta}

Dr. Sawafta is the co-founder and chief science and technology officer at Phase Change Energy Solutions. He is a serial entrepreneur, starting his first company in 2004 to develop smart materials for water and energy applications. He is a recognized global expert and thought leader in smart materials, phase change technology, computational science, biotechnology, and nanotechnology. He holds numerous patents and patent applications, authored more than 175 scientific papers, and has delivered over 200 invited talks worldwide.

\section{William Edrich}

William Edrich of Sunamp is an experienced ( $>12$ years) executive board director with an exceptional ability to combine high-level strategy and innovative solutions into practical delivery. "I look beyond what exists, have a different perspective to others and cares passionately about driving a team to achieve success. Over my working life I have established, won, and delivered $f 130 m+$ capital programs and projects in the field of energy, emerging technologies, and environment over the last 25 years."

\section{Pradeep Vitta}

Mr. Pradeep Vitta is the Energy End-Use R\&D Manager at Southern Company's Research and Development group, located in Birmingham, Alabama. Pradeep has been employed by Southern Company since 1988 and has held several significant positions as a research engineer and progressed with increased responsibility of managing the Energy End-Use R\&D group. Pradeep's current responsibilities include developing R\&D strategy, roadmaps, and overseeing the energy end-use energy efficiency and electrification R\&D projects. Pradeep is also responsible for coordinating and overseeing the Southern Company's participation in the EPRI Energy Utilization research program. 


\section{Juan Catano}

Dr. Juan Catano leads the systems analysis work for Emerson's Research Group focusing on comfort and refrigeration systems of the future and not-in-kind cooling technologies. He is the technical lead for Emerson's collaborative research initiatives with the national labs including NREL and ORNL and participates in various university consortiums discussing new technologies and building energy trends. Dr. Catano has been working on thermal energy storage for the past 4 years, with a focus on driving technology development to enhance the value proposition for building owners and utilities.

\section{Andreas Hauer}

Dr. Andreas Hauer is the head of the energy storage division at the Bavarian Center for Applied Energy Research. He is responsible for several national and international research projects focused on thermal and electrical energy storage, as well as thermally driven heat pumps and chillers for industrial and building applications. Dr. Hauer is an internationally known expert on energy storage in general and specializes on thermal energy storage. He has been involved in numerous energy storage activities within the International Energy Agency and on the German national stage.

\section{Cedar Blazek}

Cedar Blazek is a program analyst within BTO's Commercial Buildings Integration program. Her work at BTO focuses on field validation of promising commercial building technologies, partnerships with private sector building owners, and strategies to accelerate Advanced Building Construction. Cedar leads the Retail, Food Service and Grocery sector for the Better Building Initiative, runs point for the Better Buildings Alliance Technology Research Teams, and oversees research on the performance of multitechnology systems integration in real buildings.

\section{John Andrepont}

John Andrepont is the founder and president of The Cool Solutions Company, which has, since 2000, provided professional services in support of the successful technical and commercial development of TES, district cooling (DC), and turbine inlet cooling (TIC) applications. John has been involved in the development of approximately 200 TES projects and tens of district energy systems, as well as large and small TIC projects, on five continents. He is the author of numerous technical papers and articles and is the inventor of over a dozen U.S. patents.

\section{Tapan Patel}

Mr. Tapan Patel is a Mechanical Engineer at the U.S. Army Engineer Research and Development Center, Construction Engineering Research Laboratory in Champaign, Illinois where he has served since 2012. In this position, Mr. Patel is responsible for leading research projects related to energy research and development for DoD facilities. Specifically, he performs research in cybersecurity for control systems, demonstration and validation of advanced metering equipment and innovative building envelope components, testing of hydrogen fuel cell equipment and development of hardware/software prototypes. 


\section{Peter Horwath}

Mr. Peter Horwath is a world authority on phase change materials and TES systems and has advised companies and government groups from the US to Japan, Indonesia and the Middle East on their use and potential. As the co-founder, CEO and Chairman of INSOLCORP, a phase change materials/products manufacturer, Mr. Horwath is a driving force for the introduction of phase change materials into the building industry. He holds multiple patents for energy applications and is a founding member and acting President of the Phase Change Material Industry Association.

\section{Geoff Wickes}

Geoff's career spans the fields of instrumentation, controls, manufacturing, construction, information technology corporate energy management and Utility Market transformation programs. Geoff oversees the Product Management activities for NEEA's Heat Pump Water Heater program. He is actively involved with developing specifications, testing, and listing of HPWH and specifically connected aspects of water heaters leveraging CTA 2045. His background spans experience in manufacturing instruments and controls in the private sector and has worked in the field of Energy Efficiency and demand response since 2004.

\section{Tom Vega}

Tom Vega is the lead Applications Engineer for ice thermal storage projects for Baltimore Aircoil Company, where he works with building owners and their consulting engineers and contractors to size and help implement their ice thermal storage equipment. Tom has presented on the topic of thermal storage applications to consulting engineers and companies throughout the United States and has consulted on thermal storage projects for BAC throughout the world.

\section{Wim van Helden}

Dr. Wim van Helden leads the department Technology Development at AEE INTEC in Gleisdorf, Austria. In the Energy Storage group, he led and is leading several national and international research and demonstration projects, developing large scale TES and compact TES. AEE INTEC's Thermal Energy Storage group is leading in the development of compact seasonal solar thermal storage systems based on solid sorption. Wim van Helden is also board member of the European Technology and Innovation Platform on Renewable Heating and Cooling (RHC-ETIP) and member of the scientific committee of the International Renewable Energy Storage conference.

\section{Erika Gupta}

Erika Gupta is the acting program manager for the Emerging Technologies Program in EERE's Building Technologies Office. In this role she oversees a diverse portfolio of R\&D program areas, with the goal of developing cost-effective, energy-efficient, high-impact building technologies. She is also the technology manager for BTO's Sensors and Controls Subprogram. Her work leverages her controls background, focusing on building energy management controls and projects supporting controls for grid-integrated efficient buildings. 


\section{Jason Woods}

Dr. Jason Woods received his PhD from the University of Colorado in Mechanical Engineering, focusing on heat and mass transfer in thermochemical energy storage systems. He is currently a senior researcher in NREL's Building Energy Sciences group. He leads modeling and experimental projects on thermal energy storage and novel air conditioning technologies, which include multi-disciplinary research spanning materials development to systems integration.

\section{Som Shrestha}

Dr. Som Shrestha is a Building Scientist at Building Envelope Materials Research Group, Building Technologies Research and Integration Center, Oak Ridge National Laboratory. Dr. Shrestha has 12 years of research experience developing technologies to enhance building energy efficiency, five years' experience conducting energy audits of manufacturing facilities, and ten years of experience as a Mechanical Engineer. His ongoing research includes developing and evaluating building envelope that can redirect unwanted heat and coolness to a thermal loop and phase-change materials for thermal energy storage, among others.

\section{Sumanjeet Kaur}

Dr. Sumanjeet Kaur, a Research Scientist and Group Leader at Lawrence Berkeley National Laboratory, performs research on thermal energy storage. She is a material scientist and has extensive background in material synthesis and characterization, as well as in various thermal metrologies. Her current research projects include development of dynamically tunable thermal energy storage, thermal switches and standalone thermal batteries using thermochemical materials for buildings.

\section{Mitchell Ishmael}

Dr. Ishmael participated in the inaugural cohort of Innovation Crossroads, a DOE-sponsored commercialization program at Oak Ridge National Laboratory, where he co-invented icephobic heat exchange technology. He leads the company's effort to harness icephobic heat exchange's potential for efficient, low-cost, and resilient thermal energy storage systems.

\section{Joanne Huang}

Joanne Huang is a cross-functional entrepreneur with a fifteen-year background in energy, utilities, and taking a product from a napkin sketch to the market. The path of entrepreneurship has led Joanne to lead design teams, setup supply chains, and help employ over 100 local Bay Area manufacturing workers. When it comes to market impact, she has used digital channels to test brand concepts and size markets, both for her own companies and Fortune 100 corporations.

\section{Louis Desgrosseilliers}

Dr. Louis Desgrosseilliers is the CEO and co-founder of Neothermal Energy Storage Inc., founded in 2015 and located in Nova Scotia, Canada. Louis co-authored a book chapter on phase change material energy storage in "Storing Energy" published by Elsevier in 2016, and Louis' papers have appeared in Applied 
Thermal Engineering, Heat and Mass Transfer, and International Journal of Thermal Sciences. Louis is also a reviewer for Journal of Energy Storage and Journal of Building Performance Simulation.

\section{Pim Donkers}

Dr. ir. Pim Donkers has been active in the research of thermochemical materials on material and reactor level for about 10 years. In 2017 he joined TNO Materials and Solutions, where he focused on research on the active material in the Heat Battery and the reactor design around the battery. He participated in the H2020 project CREATE and since 2019 he is part of the HEAT-INSYDE team. In 2020, together with Olaf Adan, they founded Cellcius. Within Cellcius the heat battery will be further developed into a commercial system which can store loss free heat.

\section{Matthew Aguayo}

Dr. Aguayo's research background includes implementing fundamental science-based methods towards improving the materials related sustainability in buildings and transportation infrastructure. He now focuses his entrepreneurial endeavors as the Co-Founder and CEO of EnKoat and has been featured in Forbes 30 Under 30 for Energy. Matthew's passion is to develop innovative solutions that make a significant impact on the built environment. His current focus is on the design and development of novel composite envelope systems, containing thermal energy storage materials, to increase the thermal energy efficiency and resiliency of the building envelope.

\section{Arlene Anderson}

Arlene Anderson is the Lead Technology Manager within the U.S. Department of Energy (DOE), Geothermal Technologies Office Low-Temperature Geothermal Program. Ground Source Heating and Cooling, Deep Direct-Use and Advanced Energy Storage (including Reservoir Thermal Energy Storage) applications are her current Low-Temperature RD\&D focus areas. Arlene led the Thermal Task Force of world-renowned experts at Oak Ridge National Laboratory and the National Renewable Energy Lab that developed the non-electric geothermal sector analysis reported in the Geothermal Vision Study. 


\section{Appendix C. Post-Workshop Survey}

Approximately six weeks after the workshop, attendees were reengaged to solicit further information about their thoughts on priorities for thermal energy storage deployment. A survey was emailed to all workshop registrants, and they were given two weeks to submit their responses in an online form. In total, 51 registrants responded to the survey, and their responses were used to further inform the workshop findings. Summaries of the multiple-choice survey results are shown below.

Table 1. What are the biggest barriers to thermal energy storage (TES) adoption and deployment?

\begin{tabular}{|l|c|}
\hline \multicolumn{1}{|c|}{ Response Choices } & $\begin{array}{c}\text { Response } \\
\text { Breakdown }\end{array}$ \\
\hline Lack of code and standards & $14 \%$ \\
\hline Lack of incentives (no financial incentives from utility rate structures, etc.) & $22 \%$ \\
\hline \begin{tabular}{l|c|} 
Lack of awareness of system cost, performance metrics, and value \\
addition
\end{tabular} & $36 \%$ \\
\hline Lack of trained workers to implement & $14 \%$ \\
\hline Other & $14 \%$ \\
\hline
\end{tabular}

Table 2. What are some of the performance characteristics that are important when considering a TES system?

\begin{tabular}{|l|c|}
\hline \multicolumn{1}{|c|}{ Response Choices } & $\begin{array}{c}\text { Response } \\
\text { Breakdown }\end{array}$ \\
\hline Energy storage capacity & $15 \%$ \\
\hline Charging and discharging rate & $18 \%$ \\
\hline Efficiency & $14 \%$ \\
\hline Cost (capital, maintenance, and operational) & $\mathbf{2 7 \%}$ \\
\hline Ease of integration & $21 \%$ \\
\hline Other & $5 \%$ \\
\hline
\end{tabular}

Table 3. What advancements or partnerships would best encourage increased market demand for TES?

\section{Response Choices}

Tax credit and/or incentives

Awareness

Trained workforce

Other
Response

Breakdown

$35 \%$

$35 \%$

$17 \%$

$13 \%$ 
Table 4. What is the MOST important R\&D direction that needs to be pursued to enable increased commercialization of TES?

\begin{tabular}{|l|c|}
\hline Response Choices & $\begin{array}{c}\text { Response } \\
\text { Breakdown }\end{array}$ \\
\hline Standardization of codes and testing protocol & $14 \%$ \\
\hline Development of simple models to evaluate TES performance and value & $30 \%$ \\
\hline TES material and system optimization & $21 \%$ \\
\hline Increasing the utilization of TES & $23 \%$ \\
\hline Other & $12 \%$ \\
\hline
\end{tabular}

Table 5. How did you hear about the workshop?

\begin{tabular}{|l|c|}
\hline Response Choices & $\begin{array}{c}\text { Response } \\
\text { Breakdown }\end{array}$ \\
\hline BTO mailing list & $\mathbf{5 4 \%}$ \\
\hline Employer and/or colleagues & $26 \%$ \\
\hline Workshop committee & $5 \%$ \\
\hline Social media & $5 \%$ \\
\hline Other & $10 \%$ \\
\hline
\end{tabular}


